\title{
MASEX - A Dedicated Life Detection Mission on Mars
}

Authors: Y. Lin ${ }^{1}$ (ying.lin@jpl.nasa.gov, 818-393-6381), F. Zhong ${ }^{1}$, B. Henderson ${ }^{1}$, V. Abrahamsson $^{1}$, I. Kanik ${ }^{1}$, J. Gross ${ }^{1}$, L. Newlin ${ }^{1}$, W. Shubert ${ }^{1}$, L. L. H. Matthies ${ }^{1}$, C. D. Edwards ${ }^{1}$, J. Bapst ${ }^{1}$, J. Balaram ${ }^{1}$, and T. Tzanetos ${ }^{1}$

${ }^{1}$ Jet Propulsion Laboratory, California Institute of Technology, Pasadena, CA

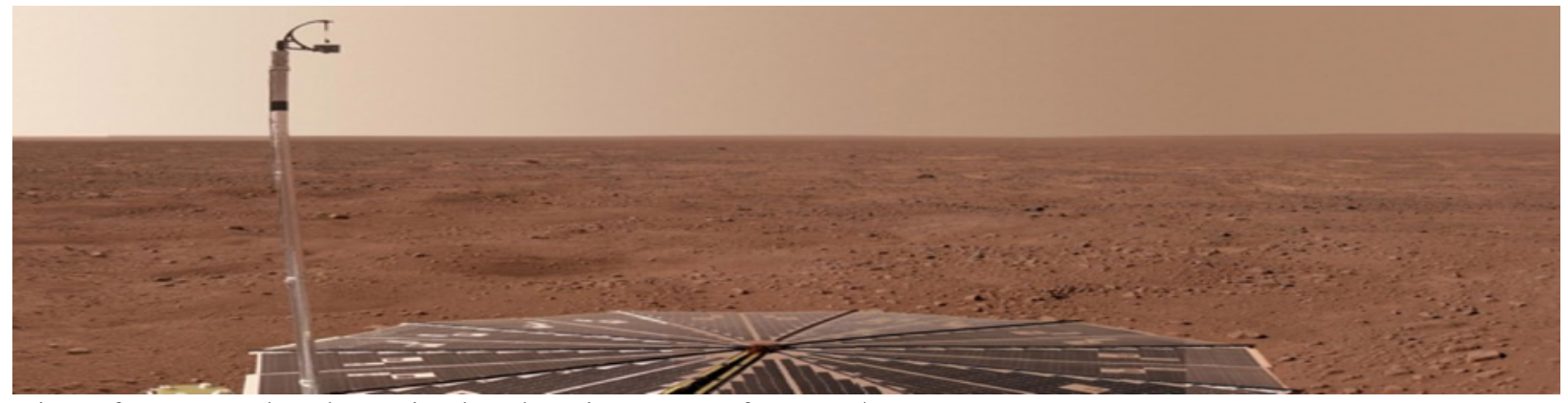

View of Mars North Polar region by Phoenix Spacecraft NASA/JPL 


\section{Introduction}

One of NASA's strategic objectives in planetary science in the current decade is to determine the potential for life elsewhere as stated in the NASA Astrobiology Strategy $(1,2)$. Exploring, identifying, and characterizing the solar system for habitability and searching for past or present life are key topics for astrobiology. Recent Mars missions have confirmed that ancient Mars was significantly wetter and warmer than previously thought. It was and could still be a habitable place for microbial life. In 2015, NASA announced evidence that liquid water exists on Mars today which raises hope that discovery of biosignatures native to Mars could be possible in the near future. So far, NASA has pursued a "follow the water" strategy on Mars and has not searched for "biosignatures of extant life" directly since the Viking missions.

In this white paper, we present an astrobiology-focused mission concept, Mars Astrobiology Science Exploration (MASEX), that targets the Mars North Polar region to look for signs of extant life, biomolecules, and organics. Our unique concept uses only $\mathrm{CO}_{2}$ and water as solvents without potentially degradation-inducing high temperature pyrolysis of the sample. The key to achieving our mission science objectives is our payload instrument system called "DREDGEM". Its name is inspired by a similar technique used by the Klondike Gold Rush prospectors to dig up the Bonanza Creek in northern Alaska to extract gold. DREDGE-M comprises two major

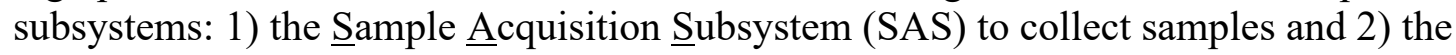

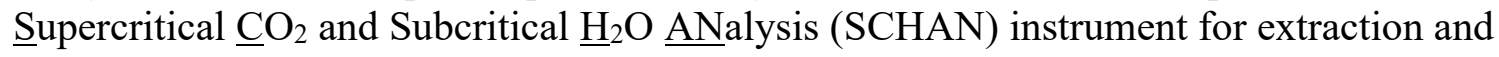
analysis of organic species at parts-per-billion (ppb) level of detection limits (3). SCHAN also includes a powerful separation capability to detect chiral amino acids, that are fundamental building blocks of terrestrial life.

\section{Background}

\subsection{Past Attempts to Detect Life and Organics on Mars}

Since the 1970s, several landed missions have attempted to answer the question of whether Mars is habitable or whether extant or extinct life may be detectable on its surface. In 1976, the twin Viking landers became the first to sample the surface of Mars for organics and life. Viking's biological experiments did not detect any conclusive metabolic activities of living microorganisms in the samples. The pyrolysis and thermal volatilization-gas chromatographmass spectrometer (TV-GC-MS) on Viking failed to find biosignatures, but did detect some chlorinated organic molecules that were initially explained as contamination from the pre-launch cleaning process (4). However, after Phoenix reported the presence of perchlorates in 2009, laboratory experiments shortly after suggested that the combination of high temperatures and perchlorates could have initiated organic degradation which resulted in the non-detection of organics (by Viking and Phoenix landers) and the observation of the chlorinated organics by Viking.

In the following years, the SAM suite on MSL's Curiosity rover obtained similar chlorinated compounds as well as thiophenes, aromatics, and aliphatics that were likely evolved species from thermal degradation of larger molecular structures (5). ESA's ExoMars rover, scheduled to launch in 2022, aims to

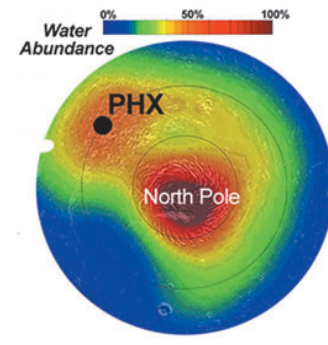

(a)

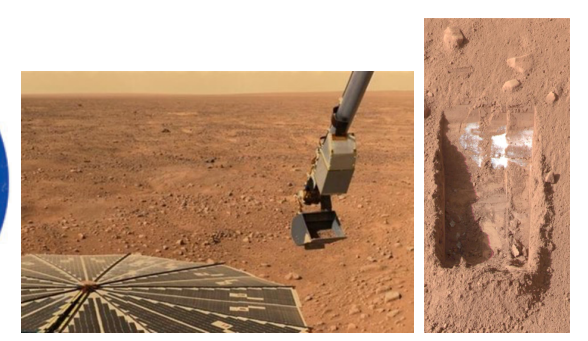

(b)

Figure 1. (a) Martian water abundance at North $>60^{\circ}$ (2). (b) Image taken on 21st day of the mission shows the ice dug out by the scoop arm on the lander. 
reduce the thermal degradation experienced in TV-GC-MS studies by including a laser desorption (LD) MS (in addition to a TV-GC-MS) for thermal volatilization of solid samples. The LD-MS enables direct vaporization of more complex molecules, but is less sensitive and does not include chromatography or chirality capabilities (6). No mission so far has demonstrated an ability to extract intact biomarkers without thermal degradation, or to extract them from intact/hardy microorganisms or fossils.

\subsection{Why Mars is Ideal for a Life Detection Mission}

In searching for extra-terrestrial life, Mars offers a number of key advantages (also see white paper by Stoke et al.). Mars is the most studied planetary body in the solar system other than Earth. There is water ice in the North Polar regions as evidenced by the Phoenix lander which revealed ice just a few $\mathrm{cm}$ below the soil surface (Figure 1). Although, there is still a lack of a broadly accepted definition of life that can guide a search for life outside Earth (7), it is a highly plausible assumption that Martian organisms would share some common properties with life on Earth. One of the assumptions is that liquid water is essential for all life forms, also on Mars. We believe that the best way to detect extraterrestrial life is to employ a comprehensive detection scheme based on capturing molecules of a wide range of polarities, rather than just water-soluble ones or just specific Earth-based molecules

\subsection{Extremophiles on Earth}

In the past two decades, tremendous advances have been made in understanding how microbes on Earth survive and propagate in extremely harsh environments. Some permafrost microorganisms found in Siberia are believed to be thousands of years old (8). Some microbes can grow at temperatures as low as $-15^{\circ} \mathrm{C}$ and metabolize at $-25^{\circ} \mathrm{C}(9)$. Viable microbial communities have been detected from Dry Valleys in Antarctica and the Chilean Atacama Desert $(10,11)$, where the conditions are somewhat similar to those on Mars. High radiation tolerance microbes seen at Chernobyl, Hanford and Fukushima can survive chronic ionizing radiation and propagate where the radiation dose is as high as $130 \mathrm{~Gy} /$ hour (12). Microorganisms on Earth adapt and thrive in places and extreme conditions which were previously considered uninhabitable. Microorganisms on Mars could be even hardier. These ground-based research studies further support the notions that there might be still viable microorganisms on Mars.

\section{Mission Science Objectives and Measurement Requirements}

The objective of MASEX is to search for the signature of live microbes, biosignature molecules, and Mars indigenous organics in the North Polar region of Mars. Table 1 summarizes MASEX's goals, scientific objectives, scientific investigations to be carried out, mission requirements and functional requirements for a landed mission scenario.

\section{Mission Architectures}

We envision three different possibilities for mission architecture. Each has its advantages and disadvantages to achieve the overall MASEX mission objectives. Phoenix, a Mars Scout mission, has successfully landed in the North Polar region and accomplished most of its scientific objectives. Its blueprint serves as confirmation of feasibility and cost estimates for all three mission architectures. In addition, the anticipated success of the Mars Helicopter Technology Demonstrator (MHTD) in the summer of 2021 will give credence for the feasibility for our third mission architecture. 
Table 1. MASEX Mission Science Traceability Matrix.

\begin{tabular}{|c|c|c|c|c|}
\hline Goals & $\begin{array}{c}\text { Science } \\
\text { Objectives }\end{array}$ & Investigations & $\begin{array}{l}\text { Measurement } \\
\text { Requirements }\end{array}$ & $\begin{array}{l}\text { Functional Requirements } \\
\text { for Landed Mission Scenario }\end{array}$ \\
\hline \multirow{5}{*}{$\begin{array}{l}\text { Search for } \\
\text { evidence of life } \\
\text { on Mars }\end{array}$} & \multirow{3}{*}{$\begin{array}{l}\text { Identify indigenous } \\
\text { organics on Mars }\end{array}$} & $\begin{array}{l}\text { Identify amino acids, } \\
\text { carboxylic acids, nucleic } \\
\text { acids, and lipids, and cover at } \\
\text { least } 50 \% \text { of the organic } \\
\text { types listed in the NASA } \\
\text { Astrobiology Ladder of Life }\end{array}$ & $\begin{array}{l}\text { Determine the relative abundances of } \\
\text { these species at ppb levels with an } \\
\text { accuracy of } 2 \% \text { or better }\end{array}$ & $\begin{array}{l}\text { Operations: Land on Mars north of } \\
60 \text { degrees latitude, collect } \\
\text { samples at depths from } 0-2 \mathrm{~m} \text {; for } \\
\text { Helicopter: } 0-5 \mathrm{~cm} \text { depth (see } \\
\text { Table } 2 \text { for architectures). }\end{array}$ \\
\hline & & $\begin{array}{l}\text { Determine the chirality of } \\
\text { amino acids on Mars }\end{array}$ & $\begin{array}{l}\text { Quantify the enantiomeric excess for } 80 \% \\
\text { of amino acids with an accuracy of } 5 \% \text { or } \\
\text { better }\end{array}$ & \multirow{3}{*}{$\begin{array}{l}\text { Instrumentation: Sensitive } \\
\text { instrumentation capable of } \\
\text { extracting polar and nonpolar } \\
\text { organics and soluble inorganics } \\
\text { from Mars soil. Interfaced with ion } \\
\text { trap or time-of-flight mass } \\
\text { spectrometer capable of } 50-1000 \\
\mathrm{~m} / \mathrm{z} \text { detection. }\end{array}$} \\
\hline & & $\begin{array}{l}\text { Search for patterns that } \\
\text { could indicate "life as we do } \\
\text { not know it" }\end{array}$ & $\begin{array}{l}\text { Perform a non-targeted analysis of } \\
\text { organics, identify large-scale patterns and } \\
\text { determine which species are responsible } \\
\text { for these patterns }\end{array}$ & \\
\hline & \multirow[b]{2}{*}{$\begin{array}{l}\text { Detect live } \\
\text { microorganisms on } \\
\text { Mars if they exist }\end{array}$} & \multirow{2}{*}{$\begin{array}{l}\text { In addition to the above, } \\
\text { detect common biomarkers } \\
\text { of earth microorganisms such } \\
\text { as DPA for bacterial spores } \\
\text { and ATP, ADP, AMP for cells }\end{array}$} & \multirow[b]{2}{*}{$\begin{array}{l}\text { Identify organic biomarkers in the lysed } \\
\text { materials to the ppb level and their } \\
\text { relative abundances to an accuracy of } 2 \% \\
\text { or better }\end{array}$} & \\
\hline & & & & \multirow{2}{*}{$\begin{array}{l}\text { Sample acquisition and } \\
\text { processing: } 0.5 \mathrm{cc} / \text { sample, depth } \\
\text { profile of } 10 \text { samples. } \\
\text { Helicopter or Rover: minimum of } 5 \text { - } \\
10 \text { sampling sites. } 1-3 \text { samples per } \\
\text { site. Diverse sites separated by } \\
100 \text { 's of meters (helicopter). }\end{array}$} \\
\hline \multirow{4}{*}{$\begin{array}{l}\text { Evaluate soil } \\
\text { chemistry to } \\
\text { understand } \\
\text { habitability }\end{array}$} & $\begin{array}{l}\text { Characterize soluble } \\
\text { inorganic chemistry } \\
\text { at the sample site }\end{array}$ & $\begin{array}{l}\text { Detect and identify } 90 \% \text { of } \\
\text { soluble cations and anions }\end{array}$ & $\begin{array}{l}\text { Quantify chloride, chlorite, chlorates, } \\
\text { perchlorates, sulfates, phosphates, } \mathrm{Na}^{+}, \\
\mathrm{NH}_{4}^{+} \text {, amines, and other cations and } \\
\text { anions present in the } 10 \mathrm{ppb}-1 \% \text { range to } \\
\text { an accuracy of } 2 \% \text { or better }\end{array}$ & \\
\hline & $\begin{array}{l}\text { Characterize the } \\
\text { presence and } \\
\text { quantify the } \\
\text { abundance of } \\
\text { perchlorates on Mars }\end{array}$ & $\begin{array}{l}\text { Detect perchlorates with } \\
\text { depth (Lander) or at several } \\
\text { sample sites (Helicopter or } \\
\text { Rover) }\end{array}$ & $\begin{array}{l}\text { Same requirements as above for inorganic } \\
\text { detections }\end{array}$ & \multirow[t]{2}{*}{$\begin{array}{l}\text { Planetary protection requirement: } \\
\text { Similar to the Phoenix mission Cat. } \\
\text { IVa requirements for landed } \\
\text { system; Cat. IVb for hardware in } \\
\text { contact with water ice and may } \\
\text { require biobarrier. }\end{array}$} \\
\hline & \multirow{2}{*}{$\begin{array}{l}\text { Evaluate water and } \\
\text { soil resources in the } \\
\text { North Polar region }\end{array}$} & \multirow{2}{*}{$\begin{array}{l}\text { Evaluate the quality of water } \\
\text { deposits and soil chemistry } \\
\text { to identify soil nutrients and } \\
\text { potential chemical hazards. }\end{array}$} & \multirow{2}{*}{$\begin{array}{l}\text { Same requirements as above for inorganic } \\
\text { and organic detections }\end{array}$} & \\
\hline & & & & Mission lifetime (baseline): 90 sols \\
\hline
\end{tabular}

Table 2. Three mission concepts with different architectures and features

\begin{tabular}{|c|c|c|}
\hline Lander & Rover & pter \\
\hline $\begin{array}{ll}\text { - } & \text { Integrated sample acquisition } \\
\text { and analysis Instrument } \\
\text { system on lander deck } \\
\text { - } \quad \text { More capable sample } \\
\text { acquisition system, 1-2 m } \\
\text { sampling depth } \\
\text { - } \quad \text { No mobility } \\
\text { - Higher contamination risk } \\
\text { with sampling near lander } \\
\text { Proven payload technology, } \\
\text { heritage from Phoenix }\end{array}$ & $\begin{array}{ll}- & \text { Integrated sample acquisition and } \\
\text { analysis Instrument system on } \\
\text { rover. }\end{array}$ & $\begin{array}{ll}\text { - } & \text { Same feature as Lander Only } \\
\text { - } & \text { Additional Aerial mobility with site } \\
\text { surveying ability. Capable of sampling } & >1 \text { km away from lander }(13,14) \\
\text { - } & \text { Separate sample acquisition payload } \\
\text { on helicopter and deliver samples to } \\
\text { extraction/analysis station on lander } \\
\text { - Shallow sampling by smaller sample } \\
\text { acquisition payload, shallower } \\
\text { sampling depth } 0-5 \mathrm{~cm} \\
\text { Heritage from MHTD Ingenuity } \\
\text { mission in 2021. Innovative but } \\
\text { higher risk }\end{array}$ \\
\hline
\end{tabular}

\section{Scientific Payload}

Our scientific payload, DREDGE-M, consists of a $\underline{\text { Sample }} \underline{\text { Acquisition }} \underline{\text { Subsystem (SAS) }}$ and an analysis instrument, SCHAN, capable of performing supercritical $\mathrm{CO}_{2}$ and subcritical

(C) 2020. California Institute of Technology.

Government sponsorship acknowledged. 
$\mathrm{H}_{2} \mathrm{O}$ analysis (Figure 2). In all three MASEX architecture scenarios the two DREDGE-M subsystems would be integrated either with a lander or on a rover. In the lander and helicopter concept an additional miniature surface sampling tool would be onboard the helicopter to collect surface samples in sites $\mathrm{km}$ away from the landing site $(13,14)$. These are mainly for inorganic and perchlorate studies and would be compared with the data collected at the landing site. Most of the organic molecules and microbes in the top $5 \mathrm{~cm}$ are unlikely to survive the radiation on Martian surface. However, for certain icy surfaces larger acquisition depths may be feasible leading to possible indications of organics.

\subsection{Sample Acquisition Subsystem (SAS)}

Several SAS candidates are available with various capabilities. Since the SCHAN subsystem only requires powdered samples, no coring requirement is needed. A pneumatic vacuum transfer system might be beneficial not only for sample transfer but also for cleaning the sampling tools and extracting loose regolith from a drill during each segment excavation. Honeybee Robotic's PlanetVac type of system (TRL 5/6) currently selected for the Dragonfly mission is one example, the 1-2 m TRIDENT drill (TRL 6) is another (15). A trade study needs to be conducted to ensure that the baseline science can be achieved and the payloads are feasible and fit within the mass, power, budget constraints of each mission architecture.

\subsection{Supercritical $\mathrm{CO}_{2}$ and Subcritical $\mathrm{H}_{2} \mathrm{O}$ Analysis (SCHAN) instrument}

The conventional way to study soil chemistry is by using organic solvent to extract hydrophobic organics and use water for soluble organic molecules and inorganic salts. The extracted molecules are then separated by chromatography using the same solvents into individual species and analyzed by analytical instruments (i.e. mass spectrometry) to identify the chemical composition of each species. Unfortunately, conventional methods are not desirable for Mars missions because bringing large quantity of organic solvents and reagents to Mars could complicate the system design and increase contamination risk. Instead of using organic solvents, we use safer alternatives, supercritical $\mathrm{CO}_{2}\left(\mathrm{scCO}_{2}\right)$ and subcritical water for end-to-end chemical analysis without any derivatization, where each analysis (nonpolar, polar and inorganic) is done in under $30 \mathrm{~min}$ (Figure 3).

$\mathrm{CO}_{2}$ in the supercritical state is nonpolar due to the low dielectric constant and its zero molecular dipole moment make it very similar to n-hexane and other nonpolar organic solvents. The Mars atmosphere contains $97 \% \mathrm{CO}_{2}$ and could potentially be harvested for an extended mission scenario. A preliminary test conducted using compressed Martian air demonstrated similar efficiency as pure $\mathrm{CO}_{2}$.

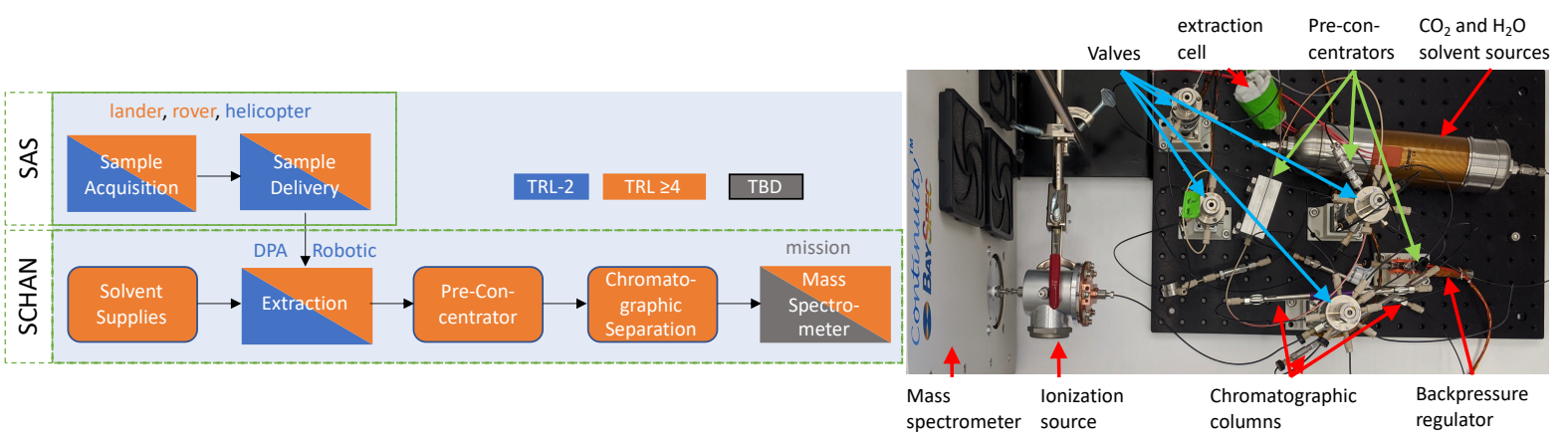

Figure 2. The DREDGE-M system consists of 7 major components as shown on the left. The SAS can be on either a mobile platform or the same lander where extraction and analysis components reside. A picture of the breadboard SCHAN instrument is shown on the right. The estimated mass for SAS is $21 \mathrm{~kg}$ (incl. drill) and $12 \mathrm{~kg}$ for SCHAN. 


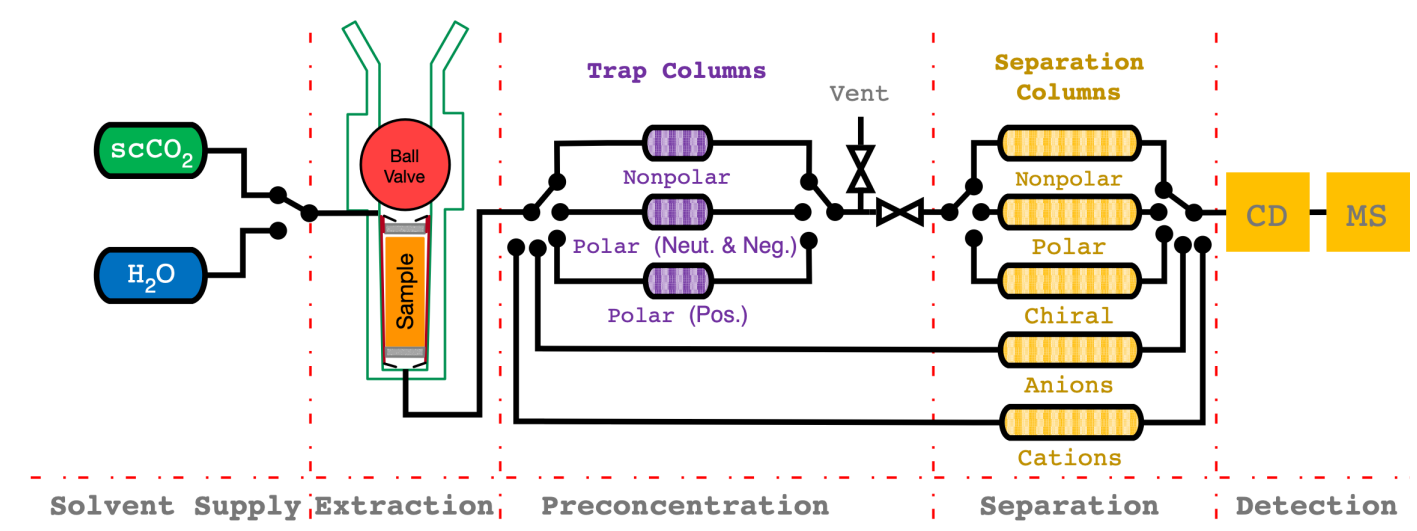

Figure 3. SCHAN consists of five sub-modules. Preconcentration and separation is achieved with trap-separation paired columns for various types of organic compounds, followed by mass spectrometry (MS) detection. A small amount of extract is diverted for direct separation of inorganics and conductivity detection (CD).

SCHAN is capable of detecting a wide range of hydrophobic molecules such as polycyclic aromatic compounds, fatty acids, pigments, sterols and glycerides with detection limits as low as 20 parts per trillion (ppt) (3). Nonpolar biomarkers are extracted with $\mathrm{scCO}_{2}$ at $40{ }^{\circ} \mathrm{C}$ at $22 \mathrm{MPa}$, or at higher temperatures $\left(<150^{\circ} \mathrm{C}\right)$ to facilitate desorption of biomarkers that are strongly bound to the regolith. The solubility in $\mathrm{scCO}_{2}$ is easily manipulated by adjusting pressure and temperature, which allows for preconcentration of lipids and consequently enables lower detection limits than any preceding in-situ instrument. The separation of extracted and preconcentrated molecules are separated by supercritical fluid chromatography with only $\mathrm{scCO}_{2}$ as a solvent, followed by MS detection.

The analysis of polar organic biosignatures such as amino acids, nucleobases, nucleotides (e.g., ATP) and dipicolinic acid (DPA, a spore indicator) is in a similar fashion performed with only carbonated water $(\mathrm{pH} \sim 3)$. Chirality is also a common feature of life on Earth. One way to distinguish organics of biotic sources from abiotic sources is to have analytical ability to separate and quantify the left-handed amino acids (L) from the right-handed ones (D) to see if there is any enantiomeric excess of one isomer. A majority of the proteinogenic amino acids are distinguished based on chirality without any organic solvents with detection limits as low as $0.25 \mathrm{ppb}$ (Figure 4). Organic biomarkers are extracted at ambient or elevated temperatures (subcritical water, $>100$ ${ }^{\circ} \mathrm{C}$ ) which has been proven to be efficient for recovering adsorbed amino acids $(16,17)$.

Analysis of both inorganic and small organic cations (e.g., alkali metals, amines and alkanolamines) and anion (e.g., perchlorates, chloride, organic acids) is unmatched by ion chromatography analysis with conductivity measurements (18). Detection limits of ca. $10 \mathrm{ppb}$ is obtained for virtually any small ionic analyte.

The comprehensive chemical analysis gives us the advantage of casting a wider net which is valuable for searching for extraterrestrial compounds that may not be identical to those on Earth.

\section{Planetary Protection}

As in any Mars mission, Planetary Protection (PP) is essential to ensure the integrity of the science measurements for the current mission, and to protect future Mars science from forward contamination. According to "Planetary Protection Provisions for Robotic Extraterrestrial Missions," NASA Procedural Requirements 8020.12D and NASA Interim Directive 8020.109A, the MASEX mission would be categorized as PP Cat IVb/IVc, with 

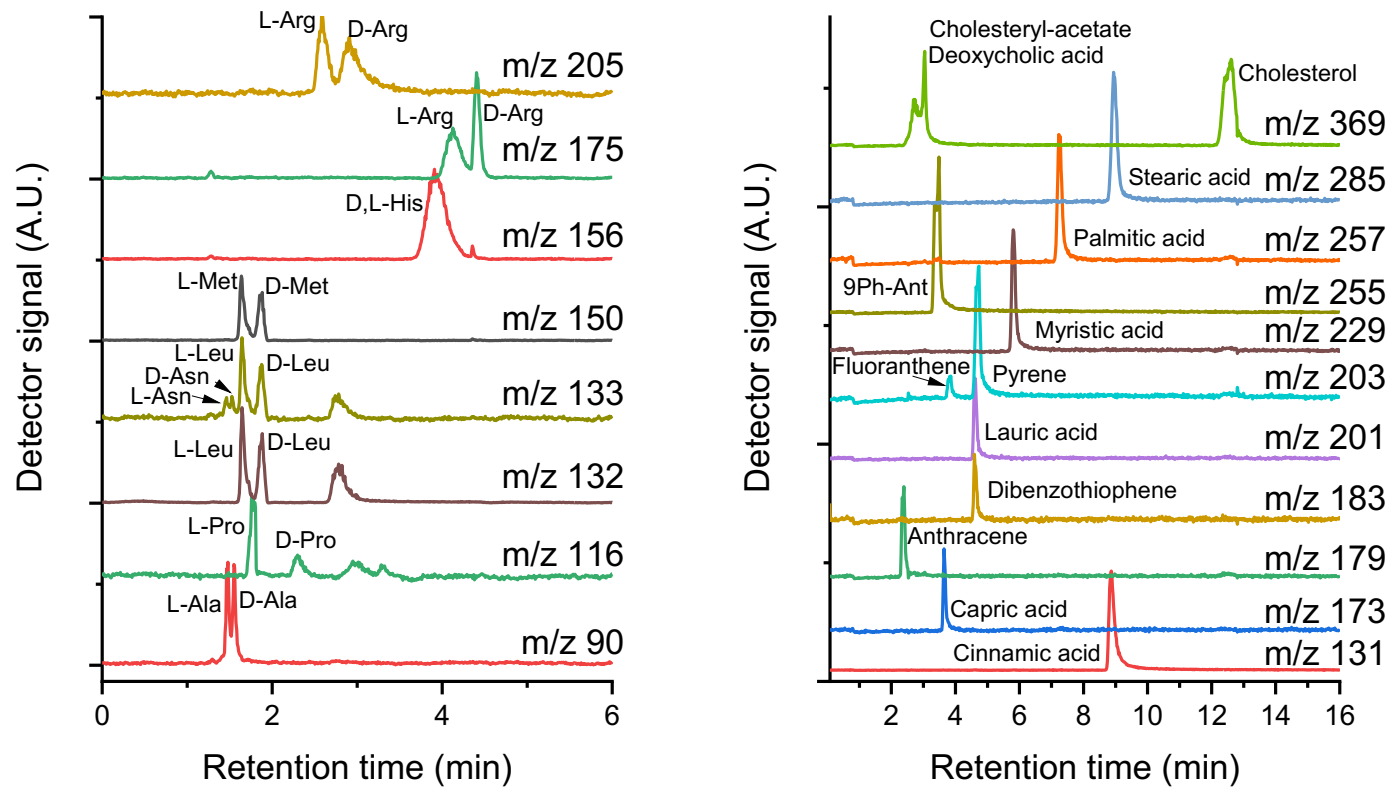

Figure 4. SCHAN is able to resolve complex mixtures that contain e.g. enantiomeric amino acids and lipids such as polycyclic aromatic compounds, fatty acids and sterols at ppb-level. The chromatographic separation resolves species based on chirality or their chemical structure and the mass spectrometer differentiates based on molecular weight.

sample-handling subsystem requirements similar to the Phoenix mission. The North Polar region is very cold. Hence, only the landing feet and sampling hardware might create transient liquid water to temporarily induce a "special region". The Lander flight system would only need to meet PP Cat. IVa requirements of a biological burden density no greater than $300 \mathrm{spores} / \mathrm{m}^{2}$, and a total biological burden of $3 \times 10^{5}$ spores on exposed surfaces, while the bioburden of hardware that would in contact with the special regions would need to be further reduced by 4 orders of magnitude, and be protected from further contamination, similar to the Phoenix Robotic Arm.

\section{Technology Development Recommendations}

In the past ten years, NASA ROSES programs has invested in $\mathrm{scCO}_{2}$ organic extraction and analysis technology under its ASTID, COLDTech, and PICASSO programs. It has finally passed the proof of concept stage (TRL 4) on both extracting and detecting hydrophobic and hydrophilic organic molecules and chirality detections from Martian soil simulants. The concept of DPA detections as biomarkers for bacterial spores has been developed and proposed to PICASSO. We are currently evaluating its capacity for inorganic salt detection by adding an ion chromatography column with a conductivity detector. The MatISSE program could help bring the integrated SCHAN capable of organic, inorganic, and DPA detection to TRL 6. The lowest TRL item is the secondary miniature sampling tool box for the helicopter or aerial sampling technology. A PICASSO funding could increase the current TRL 2 technology to TRL 4.

\section{Concluding Remarks}

In the past four decades since the Viking mission to Mars, NASA has been investing millions of dollars in planetary exploration research on sampling acquisition, biomolecule extraction and analysis, in situ life detection instrument development, and planetary protection technologies with the expectation of finding potential biosignatures elsewhere in the solar system bodies. However, Mars research has continued to be the flagship of all these efforts. As a result, 
we have gained tremendous amount of scientific knowledge on the red planet and vastly improved spacecraft building and EDL capabilities due to advances in both engineering and manufacturing techniques in exploration of Mars.

Past habitability of Mars has already been established due to the several orbital observations and in situ exploration missions carried out so far (19). The most compelling question, however, is still lingering: Did these known habitable environments on Mars lead to the emergence of life? If yes, we would expect to find some traces of life (at least extinct) there, the so-called biosignatures. Therefore, an astrobiology mission to Mars to search for potential biosignatures is becoming more compelling, timely and has a higher scientific priority than ever before. We simply cannot afford to lose the opportunity to have such a mission which is capable of determining traces of life potentially existing on a largely pristine plane, either extinct or extant, before any contamination issues arise from further robotic or human exploration.

Our successful development of the game-changing instrument system SCHAN as a payload on the MASEX mission described above would enable NASA to look for a wide variety of biosignatures that potentially exist there either from extant or extinct life on Mars. The three mission architectures presented in this white paper illustrate the possibility of different paths to achieve our astrobiology goals summarized in Table 2 . We believe with a strong engineering heritage and decades of technology advancements, the time has come for an investigation such as MASEX - to search for biosignatures that potentially exist on Mars, under the New Frontiers or Discovery program umbrella.

\section{Acknowledgement}

The research was carried out at the Jet Propulsion Laboratory, California Institute of Technology, under a contract with the National Aeronautics and Space Administration (80NM0018D0004). The information presented about the MASEX mission concept is predecisional and is provided for planning and discussion purposes only.

\section{References}

1. L. Hays. National Aeronautics and Space Administration. Washington, DC: NASA, (2015).

2. $\quad$ B. Carrier et al. Astrobiology 20, 785-814 (2020). 10.1089/ast.2020.2237

3. V. Abrahamsson et al. Anal. Bioanal. Chem. 411, 8091-8101 (2019). 10.1007/s00216-01902189-Z

4. $\quad$ M. Neveu et al. Astrobiology 18, 1375-1402 (2018). 10.1089/ast.2017.1773

5. J. L. Eigenbrode et al. Science 360, 1096-1101 (2018).

6. X. Li et al. Int. J. Mass spectrom. 422, 177-187 (2017). 10.1016/j.ijms.2017.03.010

7. C. E. Cleland et al. Origins Life Evol. Biosphere 32, 387-393 (2002). 10.1023/A:1020503324273

8. $\quad$ R. Liang et al. Appl. Environ. Microbiol. 85, (2019). 10.1128/aem.00560-19

9. $\quad$ N. C. S. Mykytczuk et al. The ISME Journal 7, 1211-1226 (2013). 10.1038/ismej.2013.8

10. R. Navarro-González et al. Science 302, 1018-1021 (2003). 10.1126/science.1089143

11. A. Crits-Christoph et al. Microbiome 1, 28 (2013). 10.1186/2049-2618-1-28

12. I. Shuryak et al. PLOS ONE 12, e0189261 (2017). 10.1371/journal.pone.0189261

13. B. Balaram et al., in AIAA Atmos. Flight Mech. Conf. (2018), pp. 23. 10.2514/6.2018-0023

14. W. R. Johnson et al., "Mars Science Helicopter Conceptual Design," NASA Technology Reports (2020)

15. K. Zacny et al. LPICo 2152, 5059 (2019).

16. J. L. Bada et al. Space Sci. Rev. 135, 269-279 (2008). 10.1007/s11214-007-9213-3

17. F. Kehl et al. Earth Space Sci. 6, 2443-2460 (2019). 10.1029/2019ea000803

18. C. P. Shelor et al. J. Chromatogr. A 1523, 300-308 (2017). 10.1016/j.chroma.2017.05.036

19. J. P. Grotzinger. Science 343, 386-389 (2014). 10.1126/science.1249944 